\title{
Responsibility Beyond CSR
}

\author{
David Bevan · Hervé Corvellec $\cdot$ Eric Faÿ
}

Published online: 10 January 2012

(C) Springer Science+Business Media B.V. 2012

I

In the space of a few years, corporate social/sustainable responsibility (CSR) has become a managerial buzzword and a major focus-if not an industry in itself-for managers, consultants, auditors, journalist, teachers, and students. But definitions of responsibility in CSR tend to be determined by the firm as a collective, or more simply representatives from the top management. And this raises a many questions, for example: in the age of CSR, how is responsibility experienced by managers as individuals? Does this responsibility differ from the responsibility of managers as representatives of a collective? If yes: how and why?

While the same word responsibility is used to depict a wide array of definitions, the meaning of responsibility varies critically as one moves from collective, or corporate responsibility to individual responsibility. The formal processes of corporate responsibility differ from those of individual responsibility. The two are not symmetrical: they impact on one another but they operate on grounds that are different and even involve different trade-offs.

Most corporations show a marked reluctance to engage with responsibility beyond a limited definition in terms of legal and economic liability. Notwithstanding, at the

\section{Bevan $(\bowtie)$}

GEM, Grenoble, France

e-mail: david.bevan@grenoble-em.com

H. Corvellec

Lund University, Lund, Sweden

E. Fä̈

EMLYON Business School, 23 Avenue Guy de Collongue, 69134 Écully, France individual and societal levels, there is a growing demand for a fuller conceptualization of the responsibility for actions undertaken in the name of corporations, and other organizations. Responsibility is not only a matter to be determined by corporations. It is also-indeed it may be even only-a critical matter for the human being that is every manager, both in and out of work, and for society at large. Events, such as, the Deepwater Horizon oil spill in the Gulf of Mexico, or the 2008 financial crisis, have largely contributed to placing responsibility at the forefront of managerial and societal demands on corporations.

We believe that a discussion of the diversity of responsibility in organizational contexts merits emphasis in research, teaching, and civil society debates. The purpose of this special issue of the Journal of Business Ethics is therefore to explore the conditions for, and the possibility of, truly responsible management; the responsibility of managers both as individuals and as agents of the firm. In particular, our purpose is to illustrate the many ways in which managers experience their personal responsibility in the field, when confronted by realities which are, or are not, accommodated by the ethical code(s) of practice produced in some remote head office.

\section{II}

The articles that we have selected are presented in the following sequence

First, in All in the Mind? Ethical Identity and the Allure of Corporate Responsibility, Max Baker and John Roberts take an original case study as the basis for challenging the conceptualization of ethical identity that asserts an alternately cynical or authentic typology for corporate responsibility. This article, relying on Levinas for insights about 
responsibility, shows how CSR practice is inherently deceptive and that a practice of responsible management is perhaps only accessible through individuals holding themselves open to the painful reality of such endless responsibility.

Next, in their ethnographic study of a French computer programming firm, Loréa Baïada-Hirèche, Jean Pasquero, and Jean-François Chanlat show that perceptions of responsibility are the result of intricate social negotiations. These negotiations take into consideration numerous symbolic and practical contextual variables, rather than arising from the application of pre-determined ethics models or norms. Conceptions of responsibility are a shared cultural construction that evolves over time and differs among participants arising from their functional position and also their personal histories and relationships within and beyond the organization. Managerial Responsibility as Negotiated Order illustrates the fluidity of the individual and collective perceptions of responsibility as social order.

Then, Jean-Phillippe Bouilloud, Vincent de Gaulejac, and Mar Perezts in Serving Two Masters: The Contradictory Organization as an Ethical Challenge for Managerial Responsibility reconsider the potentially paradoxical claim that no-one can serve two masters. This under-explored and irreducible contradiction, which has echoes in endless and familiar organizational settings, is considered as one of a class of injunctions affecting managers. They ask what managerial responsibility may mean in such contexts, and reveal that managers have to reshape their practice as a situated construction through a constant inter-mediation of interests and people. Through an original ethnographic case study looking at the money-laundering defenses at an investment bank, they reveal the phenomenon from practice. They approach responsible management as ethics-inpractice: this ethics is enacted within the frame of a structurally paradoxant system, in which managers are mediators charged with negotiating coherent behavior.

Then, again, Maya Morioka Todeschini shows how the experience(s) of responsibility is/are culturally bound. Drawing on an ethnographic approach, she offers and interpretation of how Japanese managers account for their sense and practice of responsibility around two key concepts: the concept of $b a$ that refers to shared experiences, knowledge, and responsibilities among the participants; and the concept of kokoro that is grounded in a person's spiritual strength, life energy, and capacity for empathy. Her Webs of engagement: Managerial Responsibility in a Japanese Company describes convincingly how national cultures frame and condition the sense that actor have of responsibility. This is a clear indication that responsibility should be relativized in space and time.

According to Ghislain Deslandes in the fifth article, the possibilities for truly responsible management are extremely rare in business world. Referring, in a pioneering way in this journal, to Blaise Pascal's anthropology and ethics, Deslandes underlines skeptically that human nature is driven by a desire for infinite deflected toward finite. Then, self-love and loyalty to superiors transform managers into tools for future gains, undermining the possibility for responsible management. Departing from Machiavellian cynicism in his article In Search of Individual Responsibility, Deslandes locates a means to get out this trap through his reading of Pascal. He suggests that such a reading of responsibility requires that managers cultivate their sense of truth in the relationship with themselves, and ultimately, the secret desire which opens them to infinity.

In our penultimate paper, Towards an Intermediate Position on Corporate Moral Personhood, Kevin Gibson reexamines the relationship between agency and responsible management. In particular he questions the perplexing situation in which, due to the distributed and complex chain of events which may have led to something occurring, no one may appear to be responsible for it. To show how the language of corporate personhood masks the inter-subjective essence of moral action within organizational contexts, he explores the dynamic and reciprocal exchange of values that goes on within institutional structures and settings. This leads him to expand the scope of moral consideration beyond Enlightenment notions of discrete and particular subjects and look more to an idea of embodied culture of responsibility. Such a culture makes it harder for managers to overlook morality, abdicate moral responsibility or repudiate blame. Rather they are encouraged to acknowledge that they are transformed by institutional values, and in acknowledging this, they have a potential to influence the quality of the moral values enacted in their practice.

Finally, Mollie Painter-Morland questions in Rethinking Responsible Agency in Corporations: Perspectives from Deleuze and Guattari a key assumption of most approaches to responsibility, namely that responsibility rests on "identity" and deliberate decision-making. She borrows concepts from Gilles Deleuze and Felix Guattari, such as the "body without organs" ( $\mathrm{BwO})$ or the deterritorialization and reterritorialization pair and proposes a view of responsible agency that moves away from an agency of the moral subject toward her responsiveness to the changing situation based upon intricacies of desires and social interactions. Her view of responsibility has the potential to serve even for a redefinition of the nature of accountability and commitment.

\section{III}

Departing from depersonalized approaches predominantly focused on corporate social responsibility, and which seem elsewhere to lead to complacent satisfaction (MacIntyre 
2002) and smug nihilism (Badiou 2001), the papers of this special issue underline the lived experience of social responsibility by managers. The papers featured here follow a common behavioral thread that underscores how managers live with and combine various kinds of responsibility (Takala \& Pallab 2000; Hemingway 2005; Rozuel 2011). On one hand, as the agent of a principal, managers are responsible - in the sense of being accountable - for reaching the objectives set by this principal and on which they are assessed (Ogden et al. 2005), for example speed, quality, delays, CSR, environmental impact or-of course-profitability. On the other hand, as individual moral agents, they may experience, or repress, a sense and a conscience of social or moral responsibility toward stakeholders and people in their moral space (Jensen et al. 2009). This double responsibility may turn into an existential double-bind of agency (Harmon 1995) in which there is an "irreconcilable opposition" (p. 128) between the individual and the organization. This paradoxical engagement between individual and organizational demands and expectations leads to a crucially uncomfortable dynamic in practice.

The crux of such an opposition, between two kinds of responsibility, is that the moral sense of individual responsibility can or cannot cohere with the attributive sense of responsibility that derives from being an agent of a principal. The papers in this special issue underscore in theoretical and empirical ways that there is not necessarily any de-facto convergence between these two kinds of responsibility. Moreover, that managers are therefore often faced with coping with divergence or incoherence, even conflict and contradictions, between imperatives of organisational responsibility and their sense of individual social and moral responsibility. On this account, the papers of this special issue provide several answers about: (1) how is this divergence lived and experienced, (2) how convergence may be facilitated or not, for example through national culture, laws, company policies (including CSR), or the creation of areas of autonomy.

The papers presented provide also several illustrations that being faced, in real life, with such a double responsibility may entail the experience of sweat and tears. For example, organisational agents experience CSR policies as hard-to-live-by paradoxes when the pressure of economic goals is not altered; or, as painful derision (Faÿ 2008) when it turns out that these CSR policies are nothing but attempts at image-building. It is made clear that responsibility is sited in the affective body of individual managers, and not only in their ability to reason abstractly. A recurrent theme of this special issue is that the sense of responsibility is something that is immediately experienced, lived through, and therefore embedded and embodied in the infinite totality of human life (Bevan \& Corvellec 2007).

Thus, these papers show that the ways in which managers cope with the demanding experience of responsibility are not (de)limited to exit, voice or loyalty (Hirschman 1970). Managers stay in place and bear and endure; they bring practical answers to their moral responsibility dilemmas by drawing on various kinds of arrangements that are embedded in the social and/or organizational settings of their private and professional activities. On this account, the papers provide examples of the actual sites of moral responsibility, in the sense of the locus where managers find the resources that make it possible for them to provide practical answers to the dilemmas of moral responsibility. For example, there may be various ways of accounting for an ethical desire and for a culture of responsibility, which addresses social, societal, and environmental issues, on the basis of being aware of relevant laws and policies. Such a culture of responsibility transcends the traditional ethics dichotomy of consequentialism or non-consequentialism.

This brings us to the key observation that a "morally responsible manager" is not merely a manager but a sentient, conscious being with all her/his richness and resources. How organizational actors conceive of their own and others' responsibility is rooted in a series of ontologic, anthropologic and ethical a priori, options, considerations and perspectives on the human beings and other existential issues: all of which are completely unaccounted for in the narrow view of the nature and agency of man as captured in the anthropologies of the sociopathic and conscienceless homo economicus.

As guest editors, we consider that the diversity of views on responsibility presented in the articles below opens a new understanding of the moral responsibility for managers. This invokes a responsibility they hold not only through CSR policies and their like, but through their own individual exemplarity for, and in front of, their subordinate and other stakeholders. This collection provides numerous - doubtlessly problematic but also, hopefully, useful -insights to a practice of responsibility for organisational sentient human beings.

We gratefully acknowledged the assiduous care of our panel of readers and reviewers. Thanks to Thierry Berlanda, Tomas Brytting, Bogdan Costea, Françoise Dany, Richard Ek, Lucas Introna, Tommy Jensen, Monika Kostera, Sara Louise Muhr, Claes Ohlsson, Birgitta Olsson, Monder Ram, Philippe Riot, Johan Sandström, Fred Seidel, Stefan Tengblad, Steen Valentin, Patricia Werhane, Gill Widell.

\section{References}

Badiou, A. (2001). Ethics: An essay on the understanding of evil, trans. In P. Hallward (Ed.), L'ethique: essai sur la conscience du mal. London: Verson.

Bauman, Z. (1993). Postmodern ethics. Oxford: Blackwell. 
Bevan, D., \& Corvellec, H. (2007). The impossibility of corporate ethics: For a Levinasian approach to managerial ethics. Business ethics: A european review, 16(3), 208-219.

Faÿ, E. (2008). Derision and management. Organization, 15(6), $831-850$.

Harmon, M. (1995). Responsibility as paradox: A critique of rational discourse on government. London: Sage.

Hemingway, C. A. (2005). Personal values as a catalyst for corporate social entrepreneurship. Journal of Business Ethics, 60(3), 233-249.

Hirschman, A. O. (1970). Exit, voice and loyalty. Cambridge: Harvard University Press.
Jensen, T., Sandström, J., \& Helin, S. (2009). Corporate codes of ethics and bending of moral space. Organization, 16(4), 529-545.

MacIntyre, A. (2002). After virtue. London: Duckworth \& Co.

Ogden, S., Glaister, K. W., \& Marginson, D. (2006). Empowerment and accountability: Evidence from the UK pPrivatized water industry. Journal of Management Studies, 43(3), 521-555.

Rozuel, C. (2011). The moral threat of compartmentalization: Self, roles and responsibility. Journal of Business Ethics, 102(4), 685-697.

Takala, T., \& Pallab, P. (2000). Individual, collective and social responsibility of the firm. Business ethics: A european review, 9(2), 109-118. 